Ethiopian Journal of Environmental Studies \& Management 9 (2): 220 - 227, 2016.

ISSN:1998-0507

doi: http://dx.doi.org/10.4314/ejesm.v9i2.9

Submitted: December 12, 2015

Accepted: April 11, 2016

\title{
ASSESSMENT OF ANNUAL MINIMUM TEMPERATURE IN SOME PARTS OF NORTHERN NIGERIA
}

ADAKAYI, P.E. AND *ISHAYA, $S$.

Department of Geography and Environmental Management, University of Abuja, Abuja

\begin{abstract}
This work attempts investigating the pattern of minimum temperature from 1971 to 2006, an attempt was also made to predict the pattern from 2007 to 2030 . The aim of the study therefore is to see the behaviour of minimum temperature as we study Climate Change in Northern Nigeria. This will enable us to know the trend of change for this study period. The following objectives helps in achieving the set aim; determine variations in minimum temperature, determine the trend of minimum temperature in the study area and predicting the values of the element for the period, 2007 - 2030, this was also subjected to time series analysis. The data was collected from the Nigerian Meteorological Agency, Maitama, Abuja. The length of data was thirty-six (36) years from eleven (11) stations. Simple Statistical Measures of mean, median, maximum, minimum, standard deviation, variance, skewness, kurtosis and coefficient of variability were used for discerning the patterns and distribution of minimum temperature. The results achieved indicate that the study area could be divided into two on the basis of low minimum temperature (1970s and 1980s) and high minimum temperature (1990s and 200s). During the predicted period, 2007 - 2030, mean annual minimum temperature continue to increase from $21.1^{\circ} \mathrm{C}$ in 2007 to $21.5^{\circ} \mathrm{C}$ in 2030 . Minimum temperature varies slightly in the region, and it has not varied significantly over the study period.
\end{abstract}

Key Words: Annual, Minimum temperature, predicted, variability, Northern Nigeria

\section{Introduction}

Change is an inherent characteristic of climate, therefore climate change is not an issue in any part of the world. The issue is the rapidity of change occasioned by human activities. The levels of emission of greenhouse gasses, levels of land degradation, grazing etc. contribute enormously to the rapidly changing climate (Ferro, 2005). Minimum temperature change is one extreme of climate change, so the study will give us a very good understanding of the issues of climate change. Ayoade (2003) noted that the crucial issue is the degree of variability and duration and that minor fluctuations or variations constitute not more than a "noise" in the climate series and that man can easily adapt to such. However when fluctuations in climate constitute significant departures from the normal conditions or become prolonged to constitute a new climate state, then there are problems of adjustment and the environment, man and his activities become vulnerable. The rapidity of

*Corresponding Author: Ishaya, S.

Email: ishayasunny@yahoo.com 
variations or change in climate also heightens the vulnerability of man, his socio - economic activities and the ecosystems in general to change.

Griffin (2001) noted that the climate of North Africa is influenced by the ever evolving desert/monsoon system. Within such context, it is quite natural for aridity and humidity to occur in close proximity in time and space with seasonal and longer term cyclical changes emphasizing the duality. This study will compliment earlier studies on the climate of Northern Nigeria which form part of this great North Africa.

During the Pleistocene and Holocene, a large Lake occupied the Chad Basin; it had an overspill into the Benue-Niger River system (Pachur and Altmann, 1997). The recent situation is a far cry from the past. It is well known that the Lake Chad has almost disappeared from Nigerian territory. This situation could be linked in the present study by the new emerging pattern of minimum temperature.

Pachur and Altman (1997) have noted that the divide in the Southern and South Eastern flanks of the Chad Basin have been subjected to considerable erosion since the Messenia and are now no doubt considerably lower than during that stage. The Northern divide has been by the Pliocene aridity.The role of vegetation disruption on local climate usually involves perturbations to the surface energy balance which in turn alter energy and moisture fluxes in the lower atmosphere. However, once the vegetation is depleted, the local atmosphere is further influenced by increased dust loads.

Most modelling efforts lead to a conclusion that increased mineral aerosol loads will cool the surface, warm the lower atmosphere, stabilize the atmosphere, and reduce local rainfall (Moulin et al., 1997). Besides all these, it is observed that areas in North Africa with severe desertification were warming faster than nearby areas with less magnitude of desertification. Furthermore, desertification appeared to have its greatest impact in temperatures from high-sun months and its least impact during the low-sun months.

The cold dry North East (NE) wind is enhanced by the near cloudless skies during the dry period of the year. The clear skies allow almost all insulation to be taken back to space leaving very little energy in the biosphere. With this high energy fluctuation, plant productivity is at its lowest ebb, and this partly accounts for the advancement of the Sahara. The sand particles also act as alternative surfaces, adding to further loss of energy from the biosphere. During the rainy season, the moisture content of both the atmosphere and the earth surface. Similarly the heavy cloud cover acts as blanket for terrestrial radiation thereby preventing loss of energy from the earth surface (Giorgi and Pal, 2004).

A Regional Climate Model (RCM) within a General Circulation Model (GCM) can be made for higher resolution climate fields to be produced (Giorgi and Pal, 2004). In order to get an idea of the nature of the climate change resulting from increased GHG concentrations, the mean differences between the control run (current climate) and the perturbed run (future climate) are calculated. Most climate change projections are made for fixed times (e.g. the 2020s, the 2050s, and the 2080s) or 30 years climatological periods (e.g 2071 - 2100) in the future. Changes could occur in climate statistics using these models (McGregoret. al., 2005) such as extreme events when mean states move upwards or downwards. There could also be changes in scale and shape of the distribution. 
Climate projections for the period 2071 - 2100 under A2 and B2 scenarios reveal considerable warming in all seasons ranging from $1.5^{\circ} \mathrm{C}$ to $5.5^{\circ} \mathrm{C}$ with temperatures generally $1^{\circ} \mathrm{C}-2^{\circ} \mathrm{C}$ in the case of low emissions (Beniston, 2005; Ferro, 2005; Giorgiet. al., 2004; Jones, 2001; Kjellstrom, 2004). Maximum warming occurs in Northern and Eastern Europe in winter. In summer this is found over Western and Southern Europe.

A feature of the period $1946-2004$ is symmetric warming (Klein - Tank and Konnen, 2003) meaning that there has been an approximately equal increases in the occurrence of both cold and hot extremes and no change in temperature variability that we can talk of climate change. However within this period, two "asymmetric" sub-periods, namely 19461975 and 1976-1999 may be identified due to contrasting relationship between the mean and extremes. For 1946 - 1975 a period of slight cooling occurred across Europe with an associated decrease in the number of warm extremes. However the annual number of cold extremes did not increase, implying a decrease in temperature variability. In contrast pronounced warming and an increase in the annual warm extremes at a rate of two times faster than the expected change in cold extremes, which implies increased variability characterized the period 1976 1999 (Klein - Tank and Koonen, 2003). It is in the light of all these that this work looked at minimum temperature trend in Northern Nigeria from 1971 - 2006 and estimates from $2007-2030$.

Arising from the above, a study of one climatic extreme, the minimum temperature is very essential toward an accurate understanding of climate change in Northern Nigeria. To put it more clearly, we can ask the following questions: i. Is the minimum temperature changing in the Study Area?

ii. What is the nature and direction of change?

iii. What are the characteristics of minimum temperature?

The aim of this work is to exhibit the nature and pattern of minimum temperature in the study area. Arising from this aim, the study attempted to address the following objectives; characterize minimum temperature in the study area, determine the variability and trend of the element and predict values of the element from 2007 to 2030 and determine the trend.

The main assumption of this study is that minimum temperature has not changed significantly between 1971 and 2006 and will not change significantly between 2007 and 2030.

\section{Methodology}

\section{Methods of Data Collection}

The work covers eleven (11) synoptic weather stations for thirty-six (36) years in Northern Nigeria. Series of Statistical analysis were carried out to achieve our stated objectives. This study used secondary data collected from the Nigerian Meteorological Agency, Maitama, Abuja for a period of thirty-six (36) years from eleven (11) synoptic weather stations. Necessary adjustments were made for cases of missing data such as averaging and interpolation. The eleven (11) synoptic weather stations are Bauchi, Gusau, Kano, Katsina, Kaduna, Maiduguri, Nguru, Potiskum, Sokoto, Yola and Yelwa (figure 1).

Other derivatives of minimum temperature were computed and used for further analysis. Such derivatives include Simply Statistical Measures. 


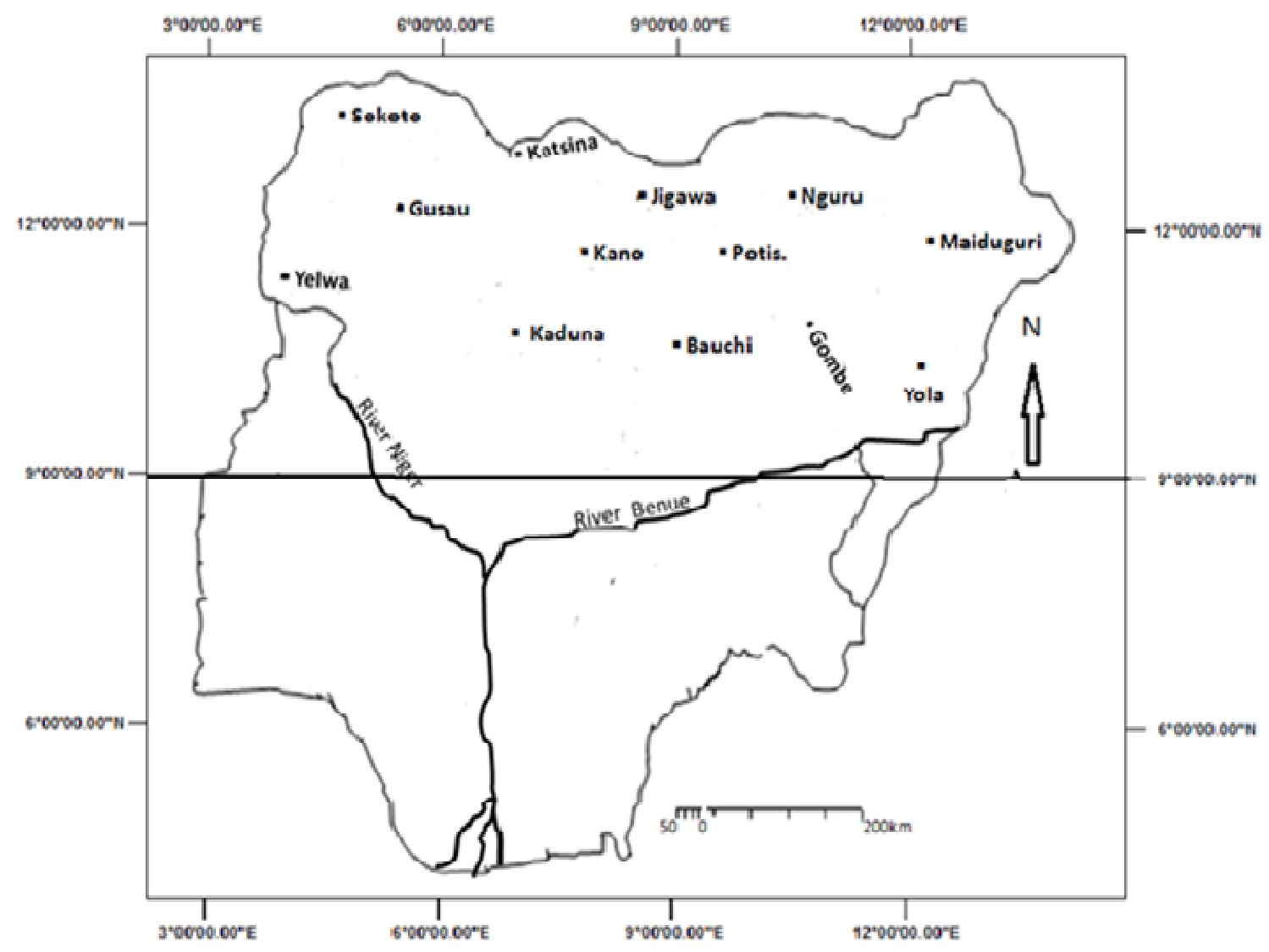

Figure 1: Climatic Stations in the Study Area

\section{Methods of Data Analysis}

The data collected and derived were subject to trend analysis, both collected and predicted. They were to show temporal patterns and distributions. The SPSS software package was used for the analysis. The normality test, Fisher's standardized coefficient of Skewness $\left(Z_{1}\right)$ and Kurtosis $\left(Z_{2}\right)$ were used to determine if the data were normally distributed to warrant the use of parametric statistics in their further analysis. These statistical analyses yielded the following statistics

- Variations in minimum temperature

- Trends in minimum temperature

\section{Results and Discussions}

The results indicate that a lower minimum temperature than the mean value occurred since 1985 to date (figure 2). 
Ethiopian Journal of Environmental Studies and Management Vol. 9 no.2 2016

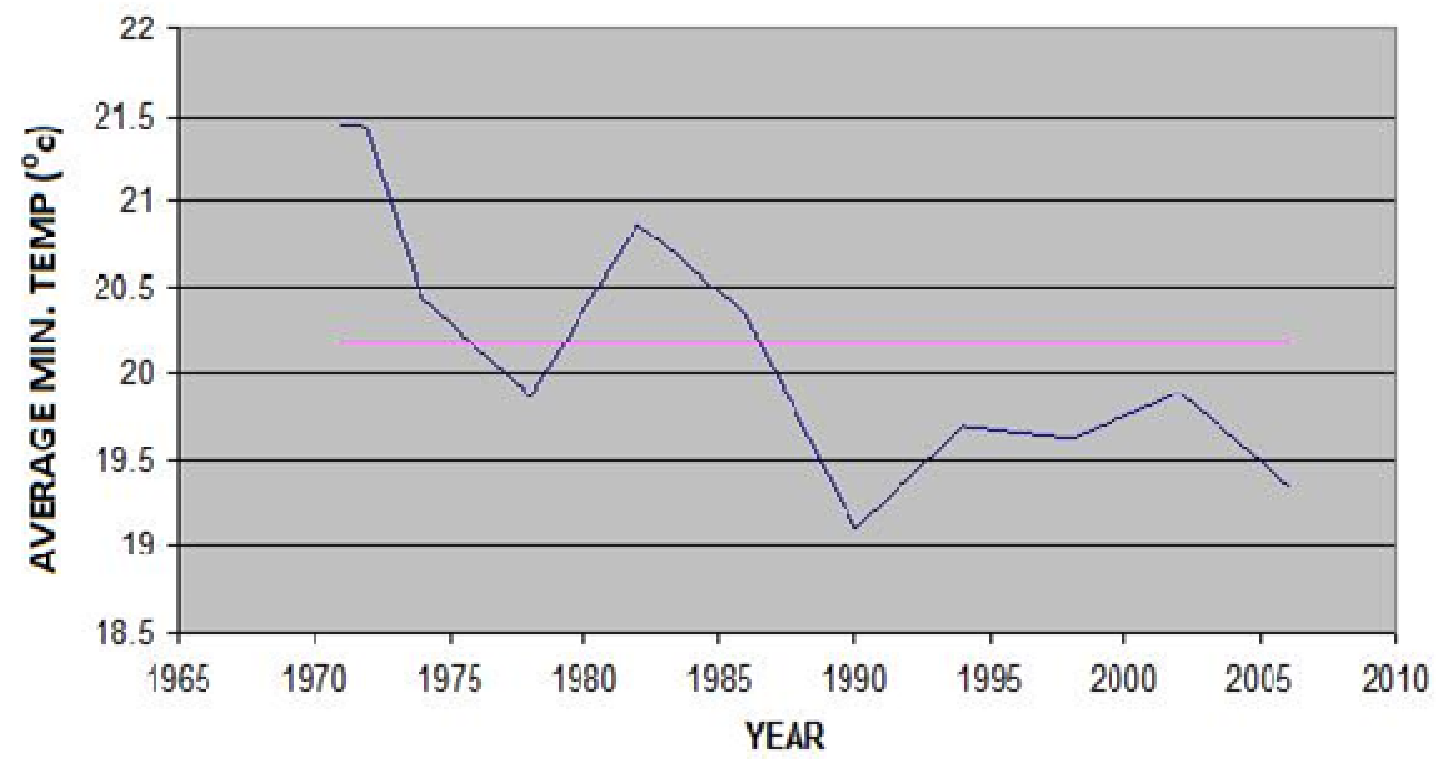

Figure 2: The time series graph of the average minimum Temperature In all the stations between 1971 and 2006

The value for 1999 has been the lowest in the recorded period of study. This is followed by the year 2006.

The time series straight line equation is of the form $y=0.0035+19.74$ (figure 3 )

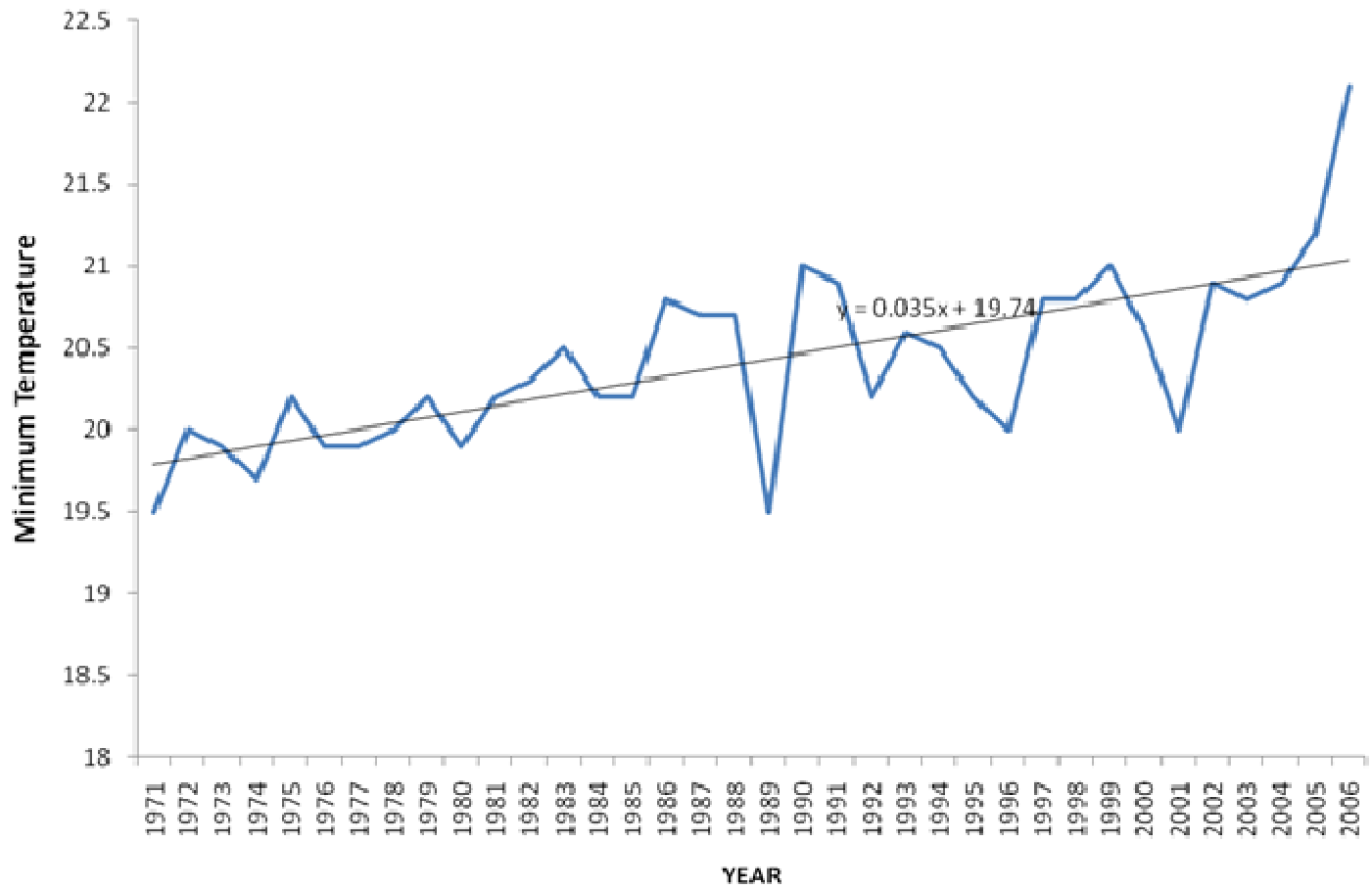

Figure 3: the time series graph of the mean minimum temperature in all the stations between 1971 and 2006

This shows the minimum temperature has been decreasing steadily. The implication here is that the range of temperature does not differ significantly. In order to see if this trend will 
continue, a time series model of ARIMA $(0,2,2)$ was used. The result of the forecast for the period 2007 to 2030 is shown in table 1 .

Table 1: Time Series Modeler

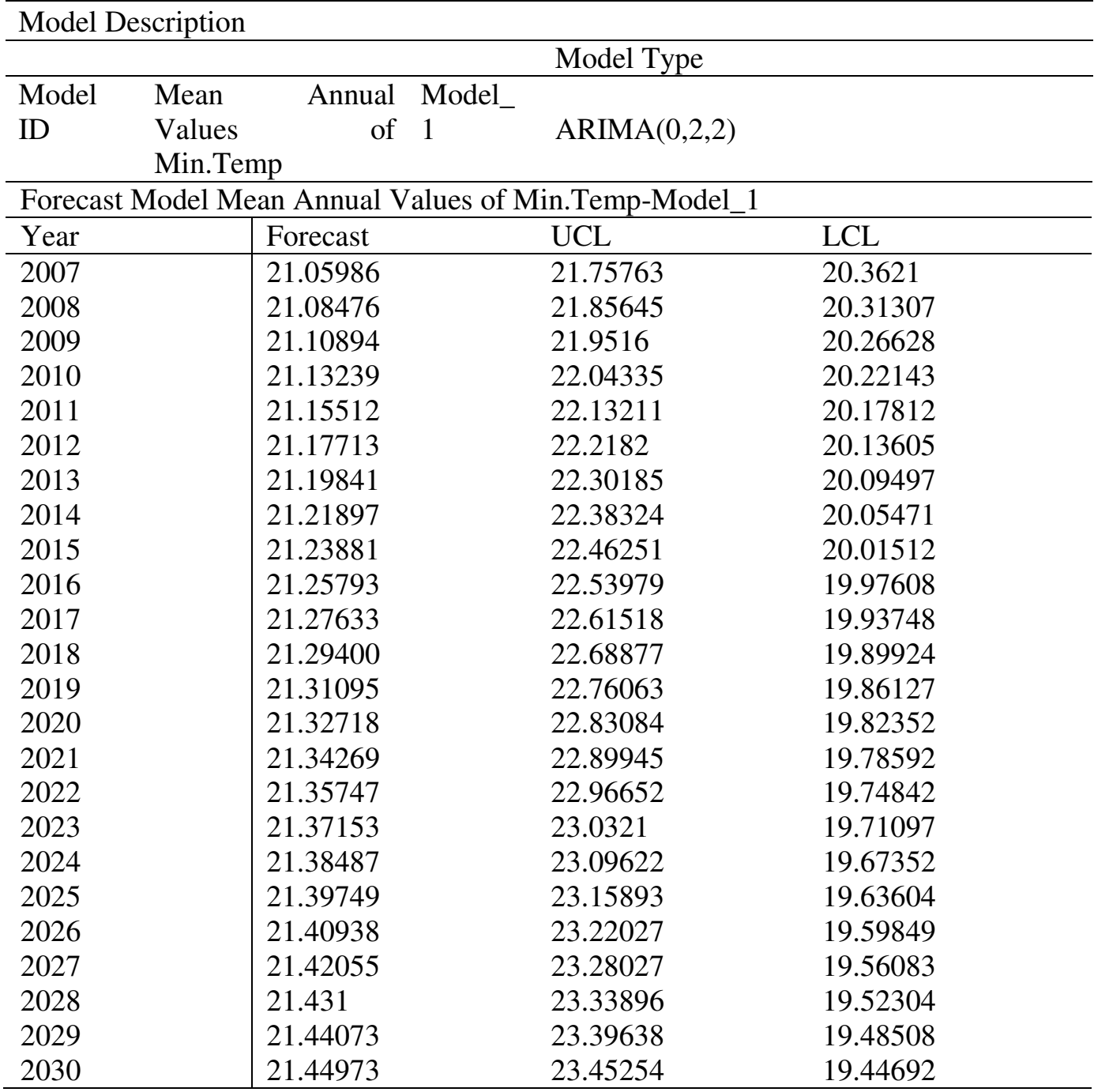

The result shows that mean minimum temperature will continue to increase from $21.1^{\circ} \mathrm{C}$ for 2007 to $21.5^{\circ} \mathrm{C}$ in 2030 . This is an increase of $0.4^{\circ} \mathrm{C}$. When this is compared to mean annual maximum temperature increase of $0.9^{\circ} \mathrm{C}$ (Adakayi, 2012) it is realized that there will be a slight increase in the range of temperature. This is an indication of a warming Northern Nigeria.

Generally we have a situation of increased rainfall in the last ten (10) years of this period of prediction, reduced number of raindays, increased mean annual maximum temperature and increase mean annual minimum temperature (Adakayi, 2012). The forecasted minimum temperatures in the study area were subjected to time series analysis and yielded a straight line equation of the form $y=-11.44+0.016 x$ and a coefficient of determination $\mathrm{R}^{2}=0.927$ (figure 4 ). 


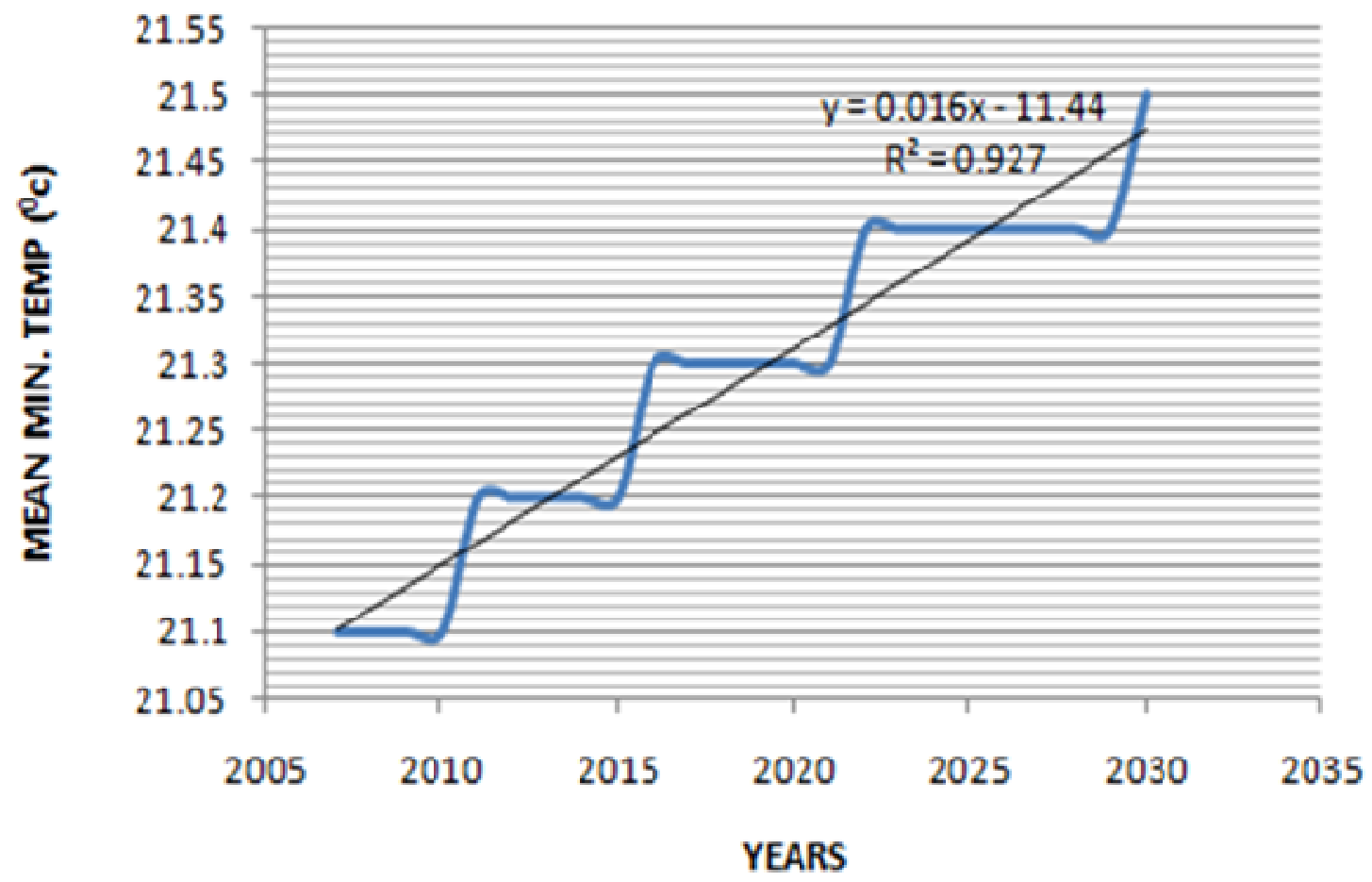

Figure 4: the time series graph of the mean min. temp. in all the stations between 2007 and 2030 (forecast)

This means that the forecast is significant. There is a general upward trend in minimum temperature between 2007 and 2030. Its range is much smaller than that of maximum temperature (Adakayi, 2012).

\section{Conclusions}

The 1970s and 1980s were years of lower minimum temperature while the 1990 s and 2000s were years of higher minimum temperature. Therefore the region could be divided into two on this basis.

During the forecast period of 2007 to 2030, minimum temperature increased from $21.1^{\circ} \mathrm{C}$ in 2007 to $21.5^{\circ} \mathrm{C}$ in 2030 , an increase of $0.4^{\circ} \mathrm{C}$ in 23 years. The annual range of minimum temperature is very slight like in earlier studies.
Departures from the mean state of minimum temperature have not been significant. This type of study must be done in other regions of Nigeria and Africa.

\section{References}

Adakayi P. E. (2012). An Assessment of Rainfall and Temperature Variation in Part of Northern Nigeria. Unpublished Ph.D Thesis Submitted to the Department of Geography and Environmental Planning, University of Jos, Plateau State, Nigeria.

Ayoade, J.O. (2003). Climate Change: A Synthesis of its Nature, causes, Effects and Management Vantage publisher Ibadan.

Beniston, M. (2005). Future extreme events in European Climate: An exploration of regional climate model 
Projections. Climate Change (submitted).

Ferro, C.A.T. (2005). Simple Techniques for describing changes in probability distributions of weather and climate. Journal of Climate (in press).

Giorgi, F., and Pal, J. (2004). "Mean, Interannual Variability and Trends in a Regional Climate change Experiment Over Europe, II". Climate change Scenarios (2071-2100), Climate Dynamics 23:839-858.

Griffin, D.L. (2001). "Aridity and Humidity: Two aspects of the late Miocene Climate of Northern Africa and the Mediterranean". Elsevier Science Canada.

Jones, C.G. (2004). The Rossby Centre Regional Atmospheric Climate Model part 1. Model Climatology and Performance for the present climate over Europe. Ambio. 33: 199210.

Kjellstrom, E. (2004). Recent and Future Signatures of Climate change in Europe. Ambio2 33: 193-198.
Klein-Tank, A.M.G. and Können, G.P. (2003). Trends $n$ Indices of Daily Temperature and Precipitation Extremes in Europe, 1946-99. Journal of Climate. 16: 3665-3680.

McGregor, G.R., Ferro, C.A.T and. Stephenson, D.B. (2005). "Projected Changes in Extreme Weather and Climate Events in Europe". In: Kirch W, Menne B., Bertollini, R. Extreme Weather and Climate Events: Publi c Health Responses. Springer, Heidelberg, pp 13-23.

Moulin, C., Lambert, C. E., Dulac, F. and Dayan, U. (1997). Control of atmospheric export of dust from North Africa in the North Atlantic Oscillation.

Pachur, H.J. and Altmann, N. (1997). "The Quarternary (Holocene, ca. 8000 a BP)". In: Schandelmeier, H. and Reynolds, $\quad$ P.-O. (eds.), Palaeogeographic Paleotectonic Atlas of North-Eastern Africa, Arabia and Adjacent Areas. Balkema, Rotterdam, pp. 111-125. 